\title{
Application of Artificial Intelligent in the Prediction of Consumer Behavior from Facebook Posts Analysis
}

\author{
Pornpimon Kachamas, Suphamongkol Akkaradamrongrat, Sukree Sinthupinyo, and Achara \\ Chandrachai
}

\begin{abstract}
The undeniable fact is that online business today has increased at a very fast pace everywhere around the globe. This happens through the widely used of Social Media, especially Facebook which is the most popular platform in the world. It would be really useful for the digital marketers, if there is a certain tool that can predict the intentions of the web patrons when the brand is posting the message to communicate with their fans or followers.

The aim of this research is to develop an analytic tool which can support online vendors to predict behaviors of the patrons according to Dentsu's AISAS perspective. An Artificial intelligent model was developed by the results from 75 specialists who evaluated the behavior that will likely occur after the comments have been posted. The results, hence, were collected and prepared for the data modelling process using the Naïve Bayes probability concept, afterwards, testing for the model's accuracy with 10-fold cross validation technique. As the previous study indicated, Naïve Bayes technique gives the best result for the behavior analysis, which is also true with this study. The predictive model for AISAS behavior from this study can give average accuracy higher than 86 percent.

When bringing the AISAS Model to test with 30 live users who are online vendors, we can conclude that the overall results of model have been greatly appreciated and effectively satisfied. Most vendors also agreed on the ease of use, which creates high chances of business opportunities.
\end{abstract}

Index Terms-AISAS, machine learning, naive-bayes classification, social media, social media analytics.

\section{INTRODUCTION}

Text Mining consists of the combination of human capacity to effectuate natural language processing (NLP) and Data Mining [1]. Data Mining is able to extract useful data from diverse resources by means of specific data identification and data pattern discovery with an objective to manage a great number of data systematically and to make data ready to be used appropriately [2].

The application of Data Mining is widely used in business environment. One of the applications of such method can be observed from data analysis in social media platforms

Manuscript received August 23, 2018; revised October 24, 2018.

P. Kachamas is with the School of Technopreneurship and Innovation Management, Graduate School, Chulalongkorn University, 254 Phayathai Rd., Phatumwan Bangkok, 10330 Thailand (e-mail: pornpimon.kac@student.chula.ac.th).

S. Akkaradamrongrat and S. Sinthupinyo are with the Department of Computer Engineering, Chulalongkorn University, 254 Phayathai Rd., Phatumwan Bangkok, 10330 Thailand (e-mail: 6070327421@student.chula.ac.th, sukree.s@chula.ac.th).

A. Chandrachai Author is with the Department of Commerce, Chulalongkorn University, 254 Phayathai Rd., Phatumwan Bangkok, 10330 Thailand (e-mail: achandrachai@gmail.com). including sentiment analysis from comment posts. It may be asserted however that we lack research using the capacity of Data Mining to conduct an in-depth analysis of consumer behavior probability on Facebook.

For the above reason, this research uses Data Mining technique to analyze consumer behavior probability from marketing communication by studying comments and messages posted on Facebook. The data is also used in Machine Learning so as to be an advantage for Facebook marketers. This research aims to assist online marketers on their attempt to communicate to consumers on Facebook in accordance with desired consumer behavior using integrated marketing according to Dentsu's AISAS model.

\section{BACKGROUND THEORIES}

\section{A. Machine Learning}

Machine learning aims to maximize the efficiency of computer program using sample data or precedent experiences. A model is developed with designated parameters in learning to perform computer program operation in order to enhance efficiency of the model using train data or past experiences. The model is developed to be capable of predicting or describing knowledge from the data, or both [3].

Machine learning bears a very close relation to statistics [4] in such a way that the concept of machine learning has derived from the theory of statistics. Breiman [5] argues that statistics suggests a greater importance of the data, whereas machine learning give higher importance to algorithm.

There are several types of machine learning including unsupervised learning, supervised learning and reinforcement learning. The author of this study resumes these types as shown in Fig. 1.

As mentioned above, the objective of this research is to conduct a study of consumer behavior probability from marketing communication on Facebook using machine learning. Machine learning effectuates data classification to cluster consumer behavior characteristics applying Naïve Bayes Classification) [7] from Bayes' Theorem. This research also applies Independence Term Assumption [8]. It is true that several probability equations, including Decision Tree, Neutral Networks, Support Vector Machine (SVM), can be applied to analyze consumer behavior, the best result in behavior analysis [9], however, is carried out by Naïve Bayesian Classifications [10]. In addition, Naïve Bayesian Classifications continues to operate to bring about the result even in case of partly lost data making this more efficient that Support Vector Machine (SVM) [11]. 


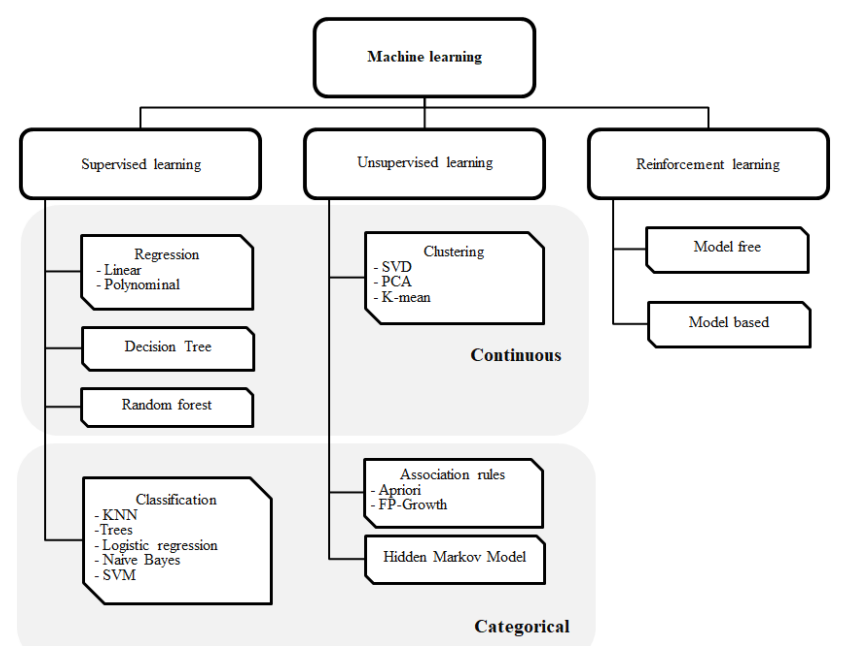

Fig. 1. Example of machine learning [6].

\section{B. AISAS Model}

Dentsu's AISAS mode relates to buying process of a consumer taking data on internet in consideration prior to buying. The model consists of Attention, Interest, Search, Action, and Share [12] which are factors taken into account in product and services purchasing decision.

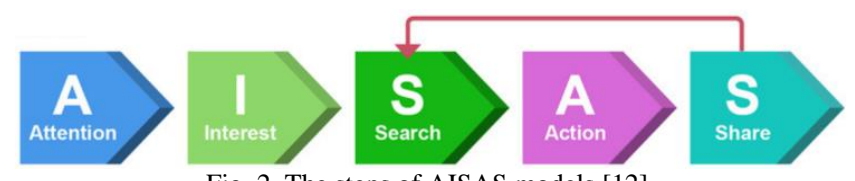

Fig. 2. The steps of AISAS models [12].

Working process of AISAS model starts when a consumer notices or sees a product, a service or an advertisement (Attention). Then, the Interest is stimulated in order to get more information about such product or service (Search). In this stage, a consumer will seek for the others' comments, reviews, posts from internet, comparison websites, formal webpages of an organization or even from a conversation with family members or friends who have been using the product or service. After that, the consumer will express his/her own opinion considering the others' opinions on that product or service. This stage leads to the decision of the consumer to buy (Action). Finally, the consumer will act as a messenger by word of mouth, conversation, or online posts of his or her opinion and impression (Sharing). Dentsu's AISAS model does not restrict the order of the occurrence of stages, they can be shifted, altered or repeated [12].

\section{Technology Acceptance Model (TAM)}

Technology Acceptance Model or TAM consists of the study with a view to understand and reach end users on how they come to accept and use technology [13]. This theory is adapted from Theory of Research Action or TRA [13], [14]. Technology Acceptance Model theory is a model to assert the acceptance of technology developed to display a clear picture of this behavior. The model also provides a clearer explanation of acceptance process of an individual to adopt technology in everyday use.

As seen in Fig. 3, TAM shows factors exercising an influence in technology use decision as follows:

1) External Variable is an external influence upon individual acceptance including belief, experience, knowledge, and understanding. To generate motivation of consumers in high valued product or service, service providers must use these external variables to stimulate consumer needs, to make them see the value in the service and use the service in fine.

2) Perceived Usefulness consists of the perception of an individual in advantages generated by using technology. That is to say that technology is perceived to be useful in development of his or her performance in work.

3) Perceived ease of Use consists of the ease used to designate individual perception so as to achieve the objective easily in terms of quantity, or the success in getting what corresponds to the need and expectation.

4) Attitude toward using and interest in using technology.

5) Behavioral Intention to Use or behavioral interest to use technology.

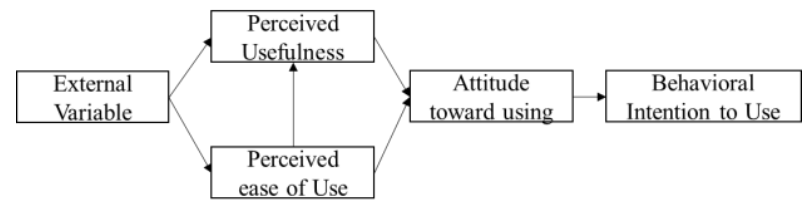

Fig. 3. Technology acceptance model (Davis, 1989).

According to TAM, the influence of the external variables is exercised on belief, attitude and interest in using technology through two perceptions, the perception of technology usefulness and the perception of technology use convenience namely, which effect the implementation of the system. The model is widely applied and adopted as a schema in successful decision in the prediction of technology acceptance. Moreover, the model illustrates the reasons related to individual technology perception in terms of usefulness and convenience so as to build behavior which can be interpreted as an interest in technology use. These effect in turn the application and the acceptance of technology.

\section{Methodology}

This research places an emphasis on supervised learning according to machine learning theory. We enter data extracted from Facebook posts. The behavior type is identified and clustered to as potential labels by purposive sampling method. Then, 81 Thai language experts randomized from ten schools around Bangkok and vicinity is invited to participate in questionnaire. After that, the samples are specified according to the appropriateness of language expertise [15]. The questionnaire is distributed to Thai language experts in order to classify the posts in accordance with AISAS model. And finally, we arrive to the conclusion indicating the correspondence of the posts with each AISAS so as to develop further prediction model for the system.

The detail of each step is given as follows:

1) The first step consists of the collection of Facebook posts. The data will be extracted and collected from three Facebook Pages with the total amount of 8,172 posts. The data collection periods of Page $A$ is between $6^{\text {th }}$ December 2012 and $8^{\text {th }}$ October 2017, Page B from $30^{\text {th }}$ September 2013 to $6^{\text {th }}$ October 2017 and Page C from $24^{\text {th }}$ September 2009 until $8^{\text {th }}$ October 2017. Once all data is completely collected, we filtrate out repeated posts, 
picture posts, video posts which do not contain message. Finally, for each page, we arrived at 1,000 posts representing the highest rate of interaction of page members, these posts is then analyzed accordingly.

2) The next step is to select messages by ordering them following the ranking of reaction amount together with the number of comments and shares from highest to lowest. The selected message must be in Thai language, clear and legible filtrated from three pages with the total of 3,000 posts: 1,000 posts equally from each page.

3) The third step consists of AISAS classification on messages. The step starts with creating labels indicating Attention, Interest, Search, Action and share namely. During this process, the researcher uses survey method to indicate the label for learning system via questionnaire. Then, the questionnaire is presented to Thai language experts from schools and universities in order to classify each post to corresponding Dentsu's AISAS integrated marketing pattern. The obtained data is considered as the set of training data for machine learning applying Naïve Bayes Classification [7].

4) The fourth step aims to verify and validate model quality. We call on K-Fold Cross Validation which is the model to detect errors in posts classification into AISAS pattern on training dataset. The random begins with clustering data into equal K-part; one K-part for testing dataset, the others K-parts for training dataset. A model will be then created to test AISAS classification of each post. After that, testing dataset is shuffled until $K$ [16] time is completed. In this test, the training dataset consists of 3,000 posts used to develop a training model applying Naïve Bayes algorithm in AISAS classification of each post. We limit the number of dataset at 10 datasets $(\mathrm{k}=10)$ in cross validation.

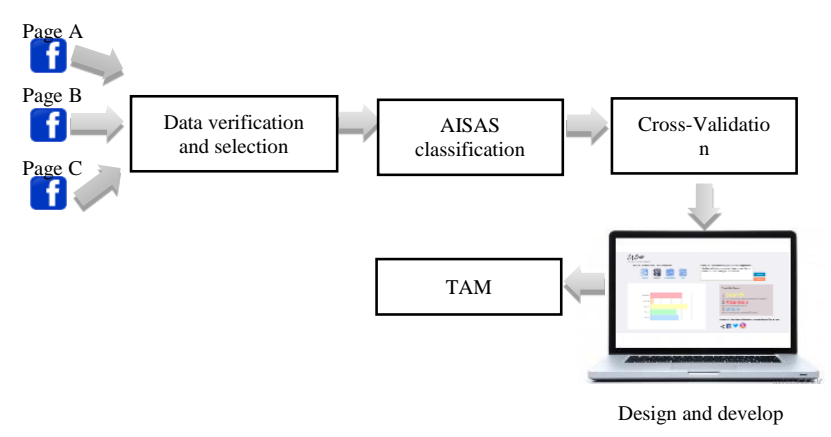

Fig. 4. Research methodology.

Accuracy defines the value of how accurate the program can predict.

$$
\text { Accuracy }=\frac{(T P+T N)}{(\mathrm{TP}+\mathrm{TN}+\mathrm{FP}+\mathrm{FN})}
$$

Recall $=$ the number of all related documents which have been extracted divided by all related documents.

Precision $=$ the number of related documents which have been extracted divided by the number of extracted document, as illustrated in Table I and equation (3), (4), (5) respectively.

$$
\text { FMeasure }_{i}=2 \times \frac{\text { Recall }_{i} \times \text { Precision }_{i}}{\text { Recall }_{i}+\text { Precision }_{i}}
$$

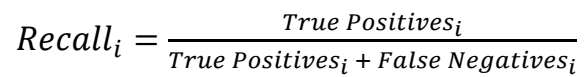

$$
\begin{aligned}
& \text { Precision }_{i}=\frac{\text { True Positives }_{i}}{\text { True Positives }_{i}+\text { False Positives }_{i}}
\end{aligned}
$$

TABLE I: CLASSIFICATION DECISION

\begin{tabular}{c|c|c}
\hline \hline \multirow{2}{*}{$\begin{array}{c}\text { Value classified by } \\
\text { classifier }\end{array}$} & \multicolumn{2}{|c}{ Value of Class $\left.\mathbf{C}_{\mathbf{i}} \mathbf{(}\right)$} \\
\cline { 2 - 3 } & Yes & No \\
\hline Yes & TP & FP \\
No & FN & TN \\
\hline \hline
\end{tabular}

1) A user interface is designed in this step together with the development of analysis system of Facebook posts so as to predict whether that post affects consumers considering AISAS pattern. The natural language processing is applied to cluster and analyze extensively so that the owners of the pages and the vendors enter the posts they wanted to communicate. This aims to test whether the probability is in line with the objectives of communication to consumers. The result is carried out in form of visualization. If it corresponds to the objective, the message will be posted directly from Web application without signing in Facebook to post. In the other hand, in case that it does not correspond to the objective, the system will suggest a group of words to business owners.

2) Technology acceptance model test is situated in this step. We select testers to test and use and send model system prototype of analysis system of messages posted on Facebook pages influencing upon consumer behavior according to Dentsu's AISAS model to marketers who possess Facebook account to test. The messages posted through Facebook pages are then collected so as to perform a study of online consumer behavior according to Dentsu's AISAA model theory. This group is comprised of 152,583 pages [17] of businesses using Facebook to communicate or operate the business in Thailand. The sample in this research is selected using Purposive Sampling method among 31 marketers present on Facebook, and who use Facebook as public relations tool to promote their business. [18]. It can be stated that the amount of 30 marketers is the minimum to have normal distribution. Normal distribution provides average value and standard deviation which shows the least and acceptable errors. In addition, normal distribution provides an explanation of the fact fairly even though there is no need of normal distribution in statistics.

The criteria of score value obtained by the questionnaire in opinion section follows the model Sig Sense [19], which divide result following Class interval, and can be interpreted as follows:

Average value between 4.21 and 5.00 means very good.

Average value between 3.41 and 4.20 means good.

Average value between 2.61 and 3.40 means average.

Average value between 1.81 and 2.60 means fair.

Average value between 1.00 and 1.80 means poor and need to be improved.

\section{RESULTS}

\section{A. Results from AISAS Classification on Messages with Naïve Bayes Method}


TABLE II: HOLISTIC VIEW OF AISAS CLASSIFICATION BY THAI LANGUAGE EXPERTS

\begin{tabular}{cccccc}
\hline \hline Classification & A & I & S & \multicolumn{1}{c}{ Ac } & \multicolumn{1}{c}{ Sh } \\
\hline Yes & 1,148 & 2,510 & 1,563 & 705 & 1,372 \\
No & 7,852 & 6,490 & 7,437 & 8,295 & 7,628 \\
Total & 9,000 & 9,000 & 9,000 & 9,000 & 9,000 \\
\%y & $12.76 \%$ & $27.89 \%$ & $17.37 \%$ & $7.83 \%$ & $15.24 \%$ \\
\%n & $87.24 \%$ & $72.11 \%$ & $82.63 \%$ & $92.17 \%$ & $84.76 \%$ \\
\hline \hline
\end{tabular}

The labels designated by Thai language experts following a set of questionnaire as shown in Table II is brought to process with RapidMiner program which calculate the probability of each word resulting in Yes or No values in each pattern in AISAS model on applied on each word from the pages.

\section{B. Results from Quality Verification of the Model of Message Classification Prediction}

Data classification will draw results comparison during simultaneous processing of the three pages. Then, the results in each page will be compared taking into consideration 1) accuracy value of the model in all classes, 2) precision value of data with precision value, and 3) accuracy value of the model with recall value in separated class.

The results of accuracy comparison of classification model with Naïve Bayes Classifications principle, and with Cross validation technique as illustrated in Table III asserts that the highest accuracy value of Attention (93.69\%) Interest $(69.56 \%)$ Search (85.20\%) Action (97.62\%) is on Page B and Share $(86.58 \%)$ is on Page A.

On the other hand, the lowest accuracy value of Attention (85.41\%) is on Page B and on Page C, Interest (57.50\%), Search $(73.47 \%)$, Share $(77.77 \%)$ is on the three pages when we process them together, and Action (93.33\%) is on Page C.

TABLE III: ACCURACY RESULT OF THE MODEL WITH ACCURACY VALUE

\begin{tabular}{crrrr}
\hline \hline Accuracy & PAGE A,B,C & \multicolumn{1}{l}{ PAGE A } & Page B & PAGE C \\
\hline Attention & $85.47 \%$ & $88.79 \%$ & $93.69 \%$ & $85.41 \%$ \\
Interest & $57.50 \%$ & $59.66 \%$ & $69.56 \%$ & $61.84 \%$ \\
Search & $73.47 \%$ & $77.58 \%$ & $85.20 \%$ & $78.36 \%$ \\
Action & $93.83 \%$ & $95.40 \%$ & $97.62 \%$ & $93.33 \%$ \\
Share & $77.77 \%$ & $86.58 \%$ & $84.57 \%$ & $81.07 \%$ \\
\hline \hline
\end{tabular}

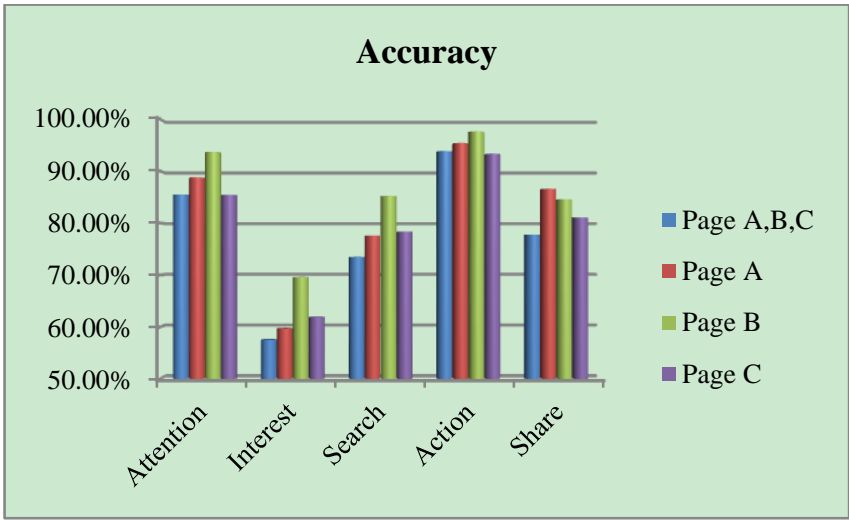

Fig. 5. Comparison of accuracy result of the model with Accuracy value
Precision value is the number of related documents which have been extracted divided by the number of extracted document, the calculation is illustrated by equation (5).

As shown in Table IV, accuracy result of the model with Precision value, the highest value of Attention (96.38\%), Interest (82.59\%), Search (91.96) is on Page B, whereas Action (98.37\%) is on Page C, and Share (95.25\%) is on Page A.

The lowest Precision value of Attention (95.97\%), Interest (78.68) is on Page C, Search (91.16\%), Action (91.16\%) is on Page A, and Share $(91.74 \%)$ is on Page B.

TABLE IV: ACCURACY RESUlt OF THE MODEL WITH PRECISION VALUE

\begin{tabular}{ccccc}
\hline \hline Precision & PAGE A,B,C & PAGE A & Page B & PAGE C \\
\hline Attention & $96.20 \%$ & $96.20 \%$ & $96.38 \%$ & $95.97 \%$ \\
Interest & $81.32 \%$ & $80.95 \%$ & $82.59 \%$ & $78.68 \%$ \\
Search & $91.86 \%$ & $91.16 \%$ & $91.96 \%$ & $91.86 \%$ \\
Action & $98.18 \%$ & $97.94 \%$ & $98.23 \%$ & $98.37 \%$ \\
Share & $93.43 \%$ & $95.25 \%$ & $91.74 \%$ & $92.88 \%$ \\
\hline \hline
\end{tabular}

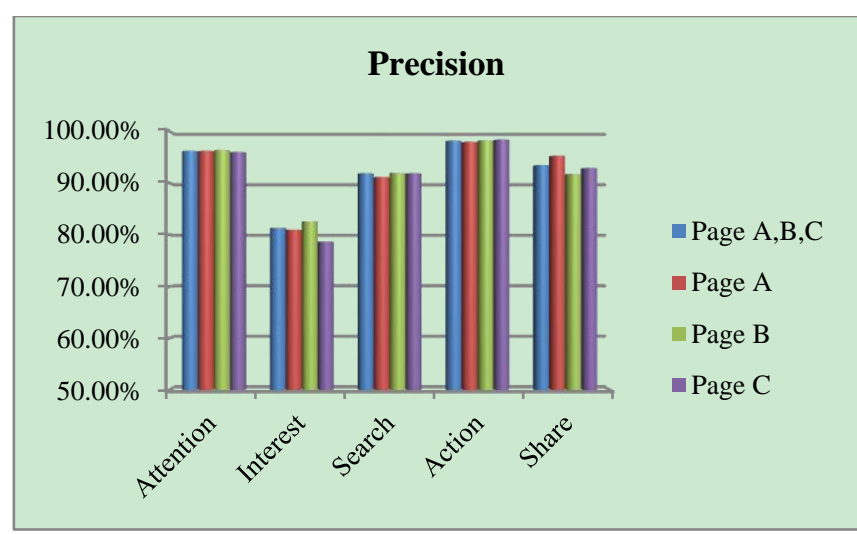

Fig. 6. Comparison of accuracy result of the model with Precision value.

Recall value the number of all related documents which have been extracted divided by all related documents as shown in equation (4).

Table V, the result of accuracy of the model with Recall value shows that the highest value of Attention (97.10), Interest $(79.67 \%)$, Search $(91.86 \%)$, Action $(91.86 \%)$, and Share $(91.43 \%)$ is on Page B.

TABLE V: ACCURACY RESUlt OF THE MODEL WITH RECALl VALUE

\begin{tabular}{ccccc}
\hline \hline Recall & PAGE A,B,C & PAGE A & Page B & PAGE C \\
\hline Attention & $88.40 \%$ & $92.00 \%$ & $97.10 \%$ & $88.53 \%$ \\
Interest & $61.37 \%$ & $65.38 \%$ & $79.67 \%$ & $71.10 \%$ \\
Search & $77.97 \%$ & $83.57 \%$ & $91.86 \%$ & $83.96 \%$ \\
Action & $95.49 \%$ & $97.34 \%$ & $99.37 \%$ & $94.80 \%$ \\
Share & $81.90 \%$ & $90.45 \%$ & $91.43 \%$ & $86.07 \%$ \\
\hline \hline
\end{tabular}

The model developed to find the probability of word groups which affect online consumer behavior in diverse aspects will be retested to find accuracy with Cross Validation technique for the total number of ten times by Naïve Bayes technique. The result carried out from the test demonstrates that we observe a greater accuracy rate of database classification of the model building when we use separated industry data than that of the overall industry data. 
Moreover, the results of probability of words according to AISAS behavior patterns, shown by positive or negative value in each pattern, can be used to evaluate the overall probability of sentences which are required to be verified in order to find out the probability. It is worth noted that each sentence could fall into more than one behavior pattern. For example, Attention and Interest while the highest probability rate is on Share.

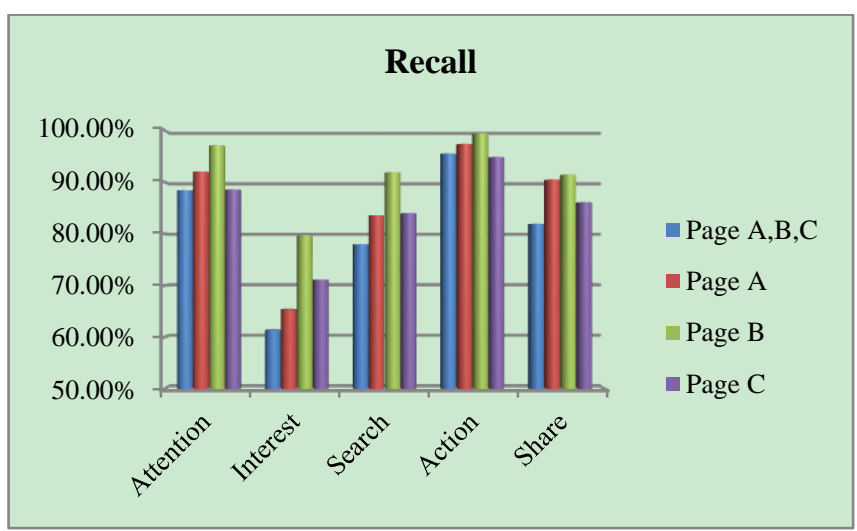

Fig. 7. Comparison of accuracy result of the model with Recall value.

\section{Result of the Design and Development of Application Prototype}

The following steps are applied in system designing.

Step 1 - Selection the product; selection of business group with whom you wish to communicate on social media.

Step 2 - Enter the message which you wish to make it public; key the data which you wish to communicate on social media, then click "analyze" to process or click "delete" in case that you wish to delete all message and retype new messages.

Step 3 - Select the channel of public communication; you can share information on social media channel which you wish to communicate our message to public such as Facebook, Twitter or Instagram.

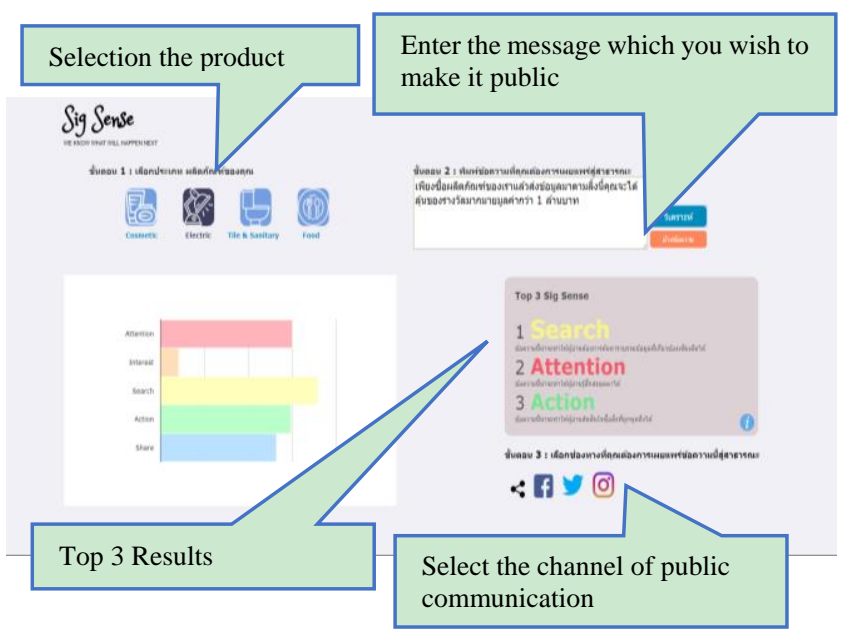

Fig. 8. Application prototype.

\section{Results of Use and Acceptance of Application Prototype}

The application prototype was tested by business or organization which uses Facebook for their public relations. Four aspects are taken into consideration; efficiency and usefulness of the system, ease of use, intention of users to use the system and overall satisfaction of the system. The results of the acceptance of technology of innovative prototype for analyzing consumer behavior probability in marketing communication illustrate that users are satisfied with innovative prototype at very good rate (average at 4.23). When we look in detail to the others aspects, the results assert that users are satisfied (1) with efficiency and usefulness of the system as described as very good (average 4.28). The majority of the sub items in this aspect are at very good result of satisfaction, except credibility of analysis which obtains an average score of 4.10 (Good). The highest score at very good result falls on suitability of the number of steps (4.45), followed by overall satisfaction of service use and Quick response of the system (in each step) (4.32 both) and finally Suitability of menu, quick access to webpage (4.23). An average result of ease of use aspect is situated at 4.20 which mean good. The results report that font size and font pattern, beautiful and easy to read and data display in clear category receive an average result at 4.23 which means very good. In the same time, Menu pattern, easy to read and use at an average of 4.19 and Well-Design, modern, interesting system at an average of 4.16 receive good result respectively. (3) The aspect of the intention to use the system shows a good result at an average score of 4.15 . The results also show that users intend to suggest the others to use (4.19) and to use the system continually (4.10).

TABLE VI: AVERAGE VALUE OF USER SATISFACTION TOWARDS PROTOTYPE INNOVATION

\begin{tabular}{|c|c|c|c|c|}
\hline \multicolumn{2}{|r|}{ Item } & Mean & S.D. & Result \\
\hline \multicolumn{5}{|c|}{$\begin{array}{l}\text { 1. Efficiency and Usefulness of the } \\
\text { system }\end{array}$} \\
\hline 1.1 & $\begin{array}{l}\text { Suitability of menu, quick access } \\
\text { to webpage }\end{array}$ & 4.23 & 0.62 & $\begin{array}{l}\text { Very } \\
\text { good }\end{array}$ \\
\hline 1.2 & $\begin{array}{l}\text { Quick response of the system (in } \\
\text { each step) }\end{array}$ & 4.32 & 0.60 & $\begin{array}{l}\text { Very } \\
\text { good }\end{array}$ \\
\hline 1.3 & Suitability of the number of steps & 4.45 & 0.68 & $\begin{array}{l}\text { Very } \\
\text { good }\end{array}$ \\
\hline 1.4 & Credibility of analysis & 4.10 & 0.75 & Good \\
\hline 1.5 & Overall satisfaction of service use & 4.32 & 0.65 & $\begin{array}{l}\text { Very } \\
\text { good }\end{array}$ \\
\hline \multicolumn{2}{|c|}{$\begin{array}{l}\text { Overall satisfaction of efficiency and } \\
\text { usefulness of the system }\end{array}$} & 4.28 & 0.44 & $\begin{array}{l}\text { Very } \\
\text { good }\end{array}$ \\
\hline
\end{tabular}

\section{Ease of use}

2 Well-Design, modern, interesting

2.2 Menu pattern, easy to read and use

Font size, font pattern, beautiful and easy to read

2.4 Data display in clear category

\begin{tabular}{|c|c|}
\hline 4.16 & 0.64 \\
\hline 4.19 & 0.70 \\
\hline 4.23 & 0.76 \\
\hline 4.23 & 0.62 \\
\hline 4.20 & 0.47 \\
\hline
\end{tabular}

Overall satisfaction of ease of use

$\begin{array}{lll}4.20 & 0.47 \quad \text { Good }\end{array}$

\begin{tabular}{cccc}
\hline 3. Attitude of system use & 4.23 & 0.62 & $\begin{array}{c}\text { Very } \\
\text { good }\end{array}$ \\
\hline 4. Intention to use the system & & & \\
$4.1 \quad$ User intends to use continually & 4.10 & 0.65 & Good \\
$4.2 \quad \begin{array}{l}\text { User intends to suggest the others } \\
\quad \text { to use }\end{array}$ & 4.19 & 0.70 & Good \\
Overall satisfaction of intention to apply & 4.15 & 0.46 & Good \\
\hline \hline
\end{tabular}

\section{CONCLUSION AND DISCUSSION}

Facebook comprises of two main functions which are the 
posting of message brands wish to communicate to consumers, and opinions and comments of consumers responding to brand communication. At present, the research or social media analysis tools tends to carry out the studies and analysis of consumer opinion with data collected from comment. The results measure consumer sentiment towards the product or service in form of positive, negative and neutral opinion. This research therefore establish the objective to analyze message posted by brands communicating to consumers so as to predict consumer behavior and to determine whether it follows online consumer behavior theory with Dentsu's AISAS model.

The study demonstrates that it would be rather to analyze and process page by page for more efficiency. This is due to the fact of the differences in business operation pattern and communication methods of each page. For example, Page A puts focus on interaction with customers by organizing activities that customers can join. On the other hand, Page B emphasizes on awareness rising to promote product to be known and understood, whereas Page $\mathrm{C}$ stimulates customers to make a decision to buy the products.

This study corresponds to the concept of theory related to online consumer behavior in buying decision following Dentsu's AISAS theory. After verifying posted messages, the research found that consumers seek for information from various sources prior to buy products and services, and they evaluate and reflect their satisfaction after buying products and services. Online social media exercise greater influence so as that consumers can search for all concerned information, gather data from existing customers as much as possible before making a decision to buy. They do not need to meet the others and ask for their opinion towards product and services. In addition, they can leave their opinion, impression and share information to others as well. This illustrates perfectly online consumer behavior in decision making process to buy.

\section{SugGeStion OF APPLICATION}

Users of the application should pay attention to spelling before posting messages. This is because the database does not cover misspelling words and this will lead to the prediction. Even though the application can predict without selection of industry, specific data will result in higher rate of accuracy. In addition, the application cannot be used to analyze every other aspect including sentiment or interaction of users in the posts. In the future however, the application can be developed and improved to be used to analyze sentiment as all-in-one analysis to facilitate application users.

Users should also buy advertisement from Facebook. This is due to the fact that Facebook restrict visibility of the posts without advertisement of Facebook. This will lead to invisibility of the products or services on Facebook.

\section{FUTURE RESEARCH}

From the conclusion and restriction of this research, we can formulate a guideline for further research for those who are interested.

1) Research on sentence, message or phrase analysis for brans in communication with customers more efficiently.

2) Development of a dictionary used in posts for advertisement, direct public relations. One word can vary in meaning and in function. Words may not be related to advertisement, public relations. Informal words are more likely to be used in posts and should be added to the dictionary such as "แซ่บ" (delish) "บูสเตอร์” (booster) "อร๊าย" (WTF). This will result in increasing efficiency of public relations.

3) Add more industries in classification so as to cluster according to AISAS model. The system can suggest suitable words for business to communicate accordingly.

4) Study of the results of AISAS and real result in business operation such as sale volume.

5) Study others languages with diversified data.

6) Develop picture post data used in advertisement, online public relations on social media so as that this data can be then analyzed and classified according to AISAS model.

7) Develop a system to resume message on posts used in advertisement, public relations using Naïve Bayes technique which cannot identify the relation of word like "ครีมหน้าขาว" (Whitening cream), the system can indicate that "ครีม" (cream) should be followed by "หน้า" (face) and “ขาว" (white). Those who are interested can study others techniques which take this issue into account.

8) Further research can collect the data from online pages about consumable goods. This actual research focuses solely on non-consumable goods.

\section{RESTRICTION}

Due to the fact that the Facebook data collection periods are situated between September 2009 and October 2017, the accuracy therefore is valid in a certain period of time. However, database is continually updated and modified and Facebook restricted the rights to access some information such as opinion posted after each post. In case those users set right to access the opinion posts only for page owners, researchers cannot collect such data to test or analyze.

\section{REFERENCES}

[1] A. Kao and S. R. Poteet, Natural Language Processing and Text Mining, Springer Science \& Business Media, 2007.

[2] R. Feldman and J. Sanger, Text Mining Handbook: Advanced Approaches in Analyzing Unstructured Data, p. 13, Cambridge University Press, 2006

[3] E. Alpaydin, Introduction to Machine Learning: MIT Press, 2014.

[4] M. I. Jordan and T. M. Mitchell, "Machine learning: Trends, perspectives, and prospects," Science, vol. 349, no. 6245, pp. 255-260, 2015.

[5] L. Breiman, "Statistical modeling: The two cultures," Statistical Science, vol. 16, no. 3, pp. 199-215, 2001.

[6] A. Harsha, "What is machine learning? Machine learning for beginners," Big Data Analytics, March, Edureka, 2018.

[7] W. L. Buntine, "Operations for learning with graphical models," Journal of Artificial Intelligence Research, vol. 2, pp. 159-225, 1994.

[8] M. A. Ghazanfar, S. A. Alahmari, Y. F. Aldhafiri et al., "Using machine learning classifiers to predict stock exchange index," International Journal of Machine Learning and Computing, vol. 7, no. 2, pp. 24-29, 2017.

[9] A. Stuart and K. Ord, Kendall's Advanced Theory of Statistics, Volume 1: Distribution Theory: Wiley, 2009. 
[10] M. N. Murty and V. S. Devi, Pattern Recognition: An Algorithmic Approach, Springer Science \& Business Media, 2011.

[11] H. Shi and Y. Liu, "Naïve bayes vs. support vector machine: Resilience to missing data," Artificial Intelligence and Computational Intelligence, pp. 680-687.

[12] K. Sugiyama and T. Andree, The Dentsu Way: 9 Lessons for Innovation in Marketing from the World's Leading Advertising Agency, McGraw-Hill, 2011.

[13] F. D. Davis, "Perceived usefulness, perceived ease of use, and user acceptance of information technology," $M I S Q$, vol. 13, no. 3, pp. 319-340, 1989

[14] I. Ajzen, "The theory of planned behavior," Organizational Behavior and Human Decision Processes, vol. 50, no. 2, pp. 179-211, 1991

[15] S. Bjurstrom and M. Plachkinova, Sentiment Analysis Methodology for Social Web Intelligence, 2015.

[16] P. Refaeilzadeh, L. Tang, and H. Liu, "Cross-validation," Encyclopedia of Database Systems, pp. 532-538, Springer, 2009.

[17] Zocialrank. (2018). Thailand Facebook Ranking.[Online]. Available: http://zocialrank.com/facebook/

[18] W. S. Gosset, "The probable error of a mean," Biometrika, vol. 6, no. 1, pp. 1-25, 1908.

[19] J. W. Best, Research in Education, Englewood Cliffs, New Jersey: Prentice-Hall, Inc., 1977.

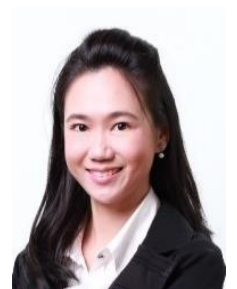

Pornpimon Kachamas was born in Bangkok Thailand, 1985. She has a B.Sc. in business administration from Assumption University. He M.Sc. is in business administration (international program) (1st honor roll) from Stamford International University. She is a Ph.D. candidate in School of Technopreneurship and Innovation Management, Graduate School at Chulalongkorn University, Thailand. Her research interest is social network marketing, social network analysis, AISAS model, and machine learning.

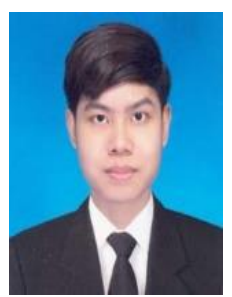

Suphamongkol Akkaradamrongrat was born in Bangkok, Thailand in 1993. He received the bachelor's degree in computer science from Department of Computer Science, Thammasat University. $\mathrm{He}$ is currently studying the master's degree in computer science at the Department of Computer Engineering, Chulalongkorn University. His research interests are machine learning, natural language processing, and social network analysis.

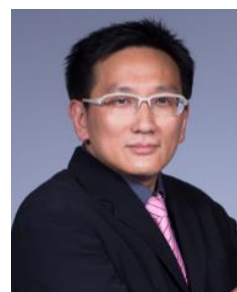

Sukree Sinthupinyo received his bachelor degree, master degree and Ph.D. (computer engineering) from Chulalongkorn University, Thailand. His main areas of research are artificial intelligence, machine learning \& pattern recognition, and engineering.

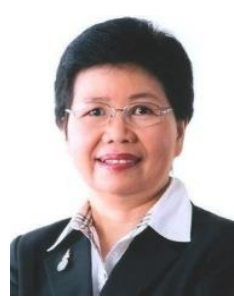

Achara Chandrachai received a bachelor degree of commerce and accountancy from Chulalongkorn University, master of business administration (2nd honor roll) from National Institute of Development Administration, Ph.D. (quantitative business analysis) of Arizona State University. She has been a professor emeritus of technopreneurship \& innovation management program since 2006 and manager of IMET (Institute of Management Education Thailand) since 2008. Her research interests are technology commercialization, business, industry analysis and strategies, business innovation. 